\title{
BASIC METHODS OF COLOR DETERMINATION IN DENTISTRY
}

\author{
Radostina Vasileva \\ Department of Prosthetic Dentistry, Faculty of Dental Medicine, \\ Medical University of Varna
}

\begin{abstract}
Determining the color of the teeth is a complicated process. Scientific research has shown that $75 \%$ of dental medicine doctors are struggling when visually determining the color of the teeth with the help of shade master. Factors like light condition, timeframe, age, sex, clothing, visual perception, redistribution of enamel masses, shine, transparency, opacity, and color of the gingiva make it harder to determine the right color of the teeth. Contemporary dentistry uses different methods and mechanisms, which can ease the work of the dentists. The uses of spectrophotometers, colorimeters, and digital images are useful instruments when analyzing the colors. These instruments are useful methods for analyzing the colors for direct and indirect restorations, procedures before and after teeth whitening, communication with indirect restorations, recreation and shade checking, as well as quality control of color recreation. In articles the authors recommend when available to combine the visual method as well as the instrumental method of color determination, because they complement each other and lead to predictable results.
\end{abstract}

Keywords: shade match, spectrophotometry, colorimetry, dental image, color

\section{INTRODUCTION}

Determining the color of the teeth is a complicated process, which is influenced by a number of factors like light condition, timeframe, age, sex, clothing, visual perception, redistribution of enamel masses, shine, transparency, opacity, light scattering, etc. In contemporary dental medicine the usual light determining through visual communication with patient, dental medicine doctor and dental technician is unsatisfactory (3). The most frequently used method for visual determining of color and shade

Address for correspondence:

Radostina Vasileva

Faculty of Dental Medicine

Medical University of Varna

84 Tzar Osvoboditel Blvd

9000 Varna

e-mail: radost11dent@abv.bg

Received: June 3, 2018

Accepted: June 29, 2018 used in dental medicine is through shade master with the information being recorded on paper. Even though the eye analyzer is a sensible organ, its disadvantages are fatigue and the subjective component of visual perception.

In Rodrigues' research $75 \%$ of dental medicine doctors are struggling when doing these measurements. Because of the following factors: time frame, light, age, sex clothing, visual perception, etc., there is a significant risk of errors.

Spectrophotometers, colorimeters are useful and suitable instruments for determination and analysis of tooth color. Different measuring mechanisms are measuring the full surface of the tooth. They provide a color map or average color of the determined area [3-5 $\mathrm{mm}$ ] onto the tooth surface. These instruments are useful methods for analyzing the colors for direct and indirect restorations, communication with indirect restorations, recreation and shade checking, as well as quality control of color recreation. 
In various articles the authors recommend, when available, to combine the visual method with the instrumental method of color determination, because they complement each other and lead to predictable results $(1,2)$.

Another suitable method for color determination is using dental photographic images taken by protocol. McLaren, T. (4-6) uses dental photography when color determining, in the communication with dental technician lab and proves in own research that the mistakes and color differences go down by $80 \%$.

The color determination protocol with the help of dental photography requires color shade (Vitaclassic, Chromascope or another equivalent to the lab shade master), premises with constant light, photographic camera, standard for white balance setting, standard and non-standard photos. Image data is available all the time in the technician lab. This way the technician obtains the required information and color reconciliation more easily and accurately in comparison with the conventional visual method (7-10,13,14,18,21-23). The basic image requirements when color determining are the following: images with enlargement 1:1 and 1:2; background in neutral grey, positioning the color sampler next to the incisor edges, parallel to the tooth axis. The best lighting for accurate color determination with camera is natural day light (in certain margins) or artificial sources of constant light with color temperature $5500^{\circ} \mathrm{K}$. (Kelvin). The flash used needs to emit light with temperature of $5500^{\circ}$ and $6000^{\circ} \mathrm{K}(1,8,9,11,13,14,18-20)$.

Khoo (18), Chu, S (1), Culic, B (11) and others describe color determination and creating of color cards according to photo images through a specific software „Clear Match“. The accurate color determination using this method requires calibrating of digital devices, in order to correctly distribute the colors $(1,8,11,18-20)$.

The combination of a visual method, digital camera, spectrophotometers and colorimeters solve the problem with inaccurate color determination. With spectrophotometry one can achieve basic color reconciliation, but according to some authors it is not shade accurate. Colorimeters show errors, when measuring semi transparent objects. According to Fondriest, $J(15,16)$ colorimeters can vary and depending on the lightning angle and high detailed teeth the data could be inaccurate.

Wee, G (19), Knösel, M. et al.(17) show in their researches that contemporary DSLR cameras with suitable calibrating protocol and specific software could be used in the process of replicating colors. Like the colorimeters, they analyze RGB values and CIE Lab color coordinates. Wee, AG points out that with CIE Lab analysis of digital images color and light changes in dentition are established and compared in procedures like whitening, dental lesions, defects, different colors in dental prosthetic constructions $(17,19,20)$.

The system CIE L.a.b (Commision Internationale de l'Eclairage et $\mathrm{L}, \mathrm{a}, \mathrm{b}$ ) is an international standard for color ranges, describing the color in digits. It is integrated in Lut software tables „Photoshop ${ }^{\text {racc }}$. The standard is useful when determining the shade of the reflected surface connected with brightness and shades at the same time. It is adequate for scientific purposes, the values are determined objectively, and could be compared with the help of statistical tests $(8,10-12,19,20)$.

The color and exterior of the teeth are complicated and dependent phenomena. The factors lightning conditions, semitransparency, opaqueness, shine, light scattering, eye perception and color perception influence the all-around perception of tooth shade. The measurement of tooth color in contemporary dental medicine is possible through the different methods, that include visual assessment of color samples, spectrophotometry, colorimetry and computer analysis of digital photographic images.

These methods are mandatory and successfully used for tooth shade changes registration and evaluation of the color after restorations and procedures for teeth whitening. Combining them would lead to more successful registration, eliminating mistakes and possibility of result comparison.

\section{REFERENCES}

1. Chu SJ1, Trushkowsky RD, Paravina RD. Dental color matching instrumentc and systems. Review of clinical and research aspects. J Dent. 2010;38(Suppl 2):e2-16. doi: 10.1016/j.jdent.2010.07.001.

2. Kim-Pusateri S1, Brewer JD, Davis EL, Wee AG. Reliability and accuracy of four dental shade- 
matching devices. J Prosthet Dent. 2009;101(3):193-

9. doi: 10.1016/S0022-3913(09)60028-7.

3. Liang $\mathrm{CH}$, Cheng YA, Hong HH, Hsieh HC. Stability and reproducibility of an amateur digital camera for dental photography. J Dent Sci. 2007; 2(3):157-63. doi : 10.30086/JDS.200709.0005.

4. McLaren E. The essential elements of evaluating and communicating tooth colour. Cosmetic Den-tistry. 2012.

5. McLaren E, Shoenbaum T. Digital photography enhances diagnostics, communication and documentation. Compend Contin Educ Dent. 2011;32 (Spec No 4):36-8.

6. McLaren E, Chang Y. Photography and Photo-shop: Simple Tools and Rules for Effective and Accurate Communication. Inside Dentistry. 2006;2(8):97-101.

7. Chao-Hua Liang et al. Stability and reproducibility of an amateur digital camera for dental photography. J Dent Sci, 2007; 3.

8. Cheung V, Westland S. Methods for Optimal Color Selection. J Imaging Sci Technol. 2006; 50(5):481-8. doi: 10.2352/J.ImagingSci.Technol. (2006)50:5(481).

9. Chu J. The science of color and shade selection in aesthetic dentistry. Dent Today. 2002; 21(9):86-9.

10. Bengel W. Digital photography and the assessment of therapeutic results after bleaching procedures. J Dent Restor Dent. 2003; 15(Suppl 1): 21-32.

11. Culic B, Dudea D, Prejmerean V, Culic C, Colosi H, Alb C. Obtaining natural tooth color with digital photography - clinical study on 30 patients. Clujul Med. 2011;84(4):524-7.

12. Farah, R. Agreement Between digital image analy-sis and clinical spectrophotometer in $\mathrm{CIEL}^{\star} \mathrm{C}^{\star}$ ho coordinate differences and total color difference measurements of dental ceramic shade tabs. Int J Esthet Dent, 2016;11(2):234-45.

13. Dalloca L, Pasquadio C, Freedman G. Digital and Analog Photography. Contemp Esthet Dent. 2012.

14. Fernandes A, Lakhani D, Herekar M. A survey on variability in shade selection by practicing dentists. Int J Esthet Dent. 2011; 6(2):198-204.

15. Fondriest J. Improving photographic strategies in shade communication. J Cosmet Dent. 2003;19(3):70-4.
16. Fondriest $\mathrm{J}$. The use of dental colorimeters in shade communication. J Cosmet Dent. 2004.

17. Knösel M, Reus M, Rosenberger A, Ziebolz D. A novel method for testing the veridicality of dental colour assessments. Eur J Orthod. 2012;34(1):19-24. doi: 10.1093/ejo/cjq142.

18. Khoo T. A comparison between a photographic shade analysis system and conventional visual shade matching method. Iowa Research Online (IRO); 2015.

19. Wee AG, Lindsey DT, Kuo S, Johnston WM. Color accuracy of commercial digital cameras for use in dentistry. Dent Mater. 2006;22(6):553-9. doi:10.1016/j.dental.2005.05.011.

20. Sluzker A, Knosel M. Sensitivity of digital dental photo CIE l. a. b. analysis compared to spectrophotometer clinical assessment over 6 months. Am J Dent. 2011;24(5):300-4.

21. Seino H. Dental imagination a record of techniques and feelings. Quintessence. 1988.

22. Rosenstiel S, Land M, Fujimoto J. Contemporary fixed prosthodontics. Elsevier; 2016.

23. Mahn E. Clinical dental photography. Part II. Protocol for shade taking and communication with the lab. Int Dent Aust. 2013; 8:34. 